\title{
Anxiety, Depression, and Spirituality Among Caregivers of Patients With Alzheimer Disease
}

\section{Roya Samadii, ${ }^{1,}$, Naghmeh Mokhber ${ }^{1,2,}$, Farhad Faridhosseini ${ }^{1,2}$, Mehri Baghban Haghighi ${ }^{3}$, Shervin Assari ${ }^{4,5,6}$}

1. Psychiatry and Behavioral Sciences Research Center, Mashhad University of Medical Sciences, Mashhad, Iran

2. Department of Psychiatry, Faculty of Medicine, Mashhad University of Medical Sciences, Mashhad, Iran

3. Faculty of Medicine, Mashhad University of Medical Sciences, Mashhad, Iran

4. Social Determinants of Health Research Center, University of Social Welfare and Rehabilitation Sciences, Tehran, Iran

5. Center for Research on Ethnicity, Culture, and Health (CRECH), University of Michigan School of Public Health, Ann Arbor, USA

6. Department of Psychiatry, School of Public Health, University of Michigan, Ann Arbor, USA

*Corresponding Author: Naghmeh Mokhber, MD, Psychiatry and Behavioral Sciences Research Center, Ibn-e-Sina Hospital, Faculty of Medicine, Mashhad University of Medical Sciences, Mashhad, Iran

Email: pbsrc@mums.ac.ir

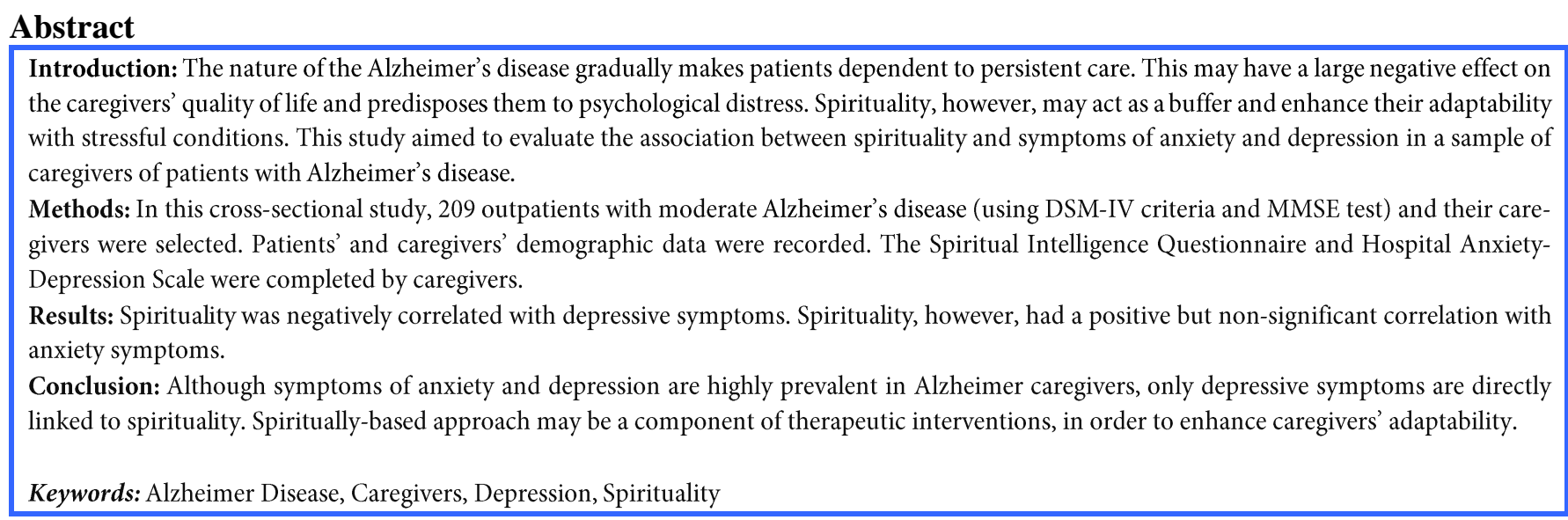

Article History: Received: 16 Jul 2014; Revised: 25 Sep 2014; Accepted: 1 Nov 2014

Cite this article as: Samadi R, Mokhber N, Faridhosseini F, Baghban Haghighi M, Assari S. Anxiety, depression, and spirituality among caregivers of patients with Alzheimer disease. Int J Travel Med Glob Health. 2015;3(1):29-35.

\section{Introduction}

Alzheimer's disease is the most common cause of dementia in elderly, which is becoming more prevalent, as a result of the increase of life expectancy [1]. In addition to cognitive symptoms, that constitute the core part of the disease, coexisting behavioral, mood, anxiety and other symptoms gradually deteriorate the outcomes and make the patients quite dependent to persistent caregiving [2].

Caregivers - who are often family members of patients - are at high risk of psychological distress and physical disorders and even mortality [3]. The amount of stress that is experienced by caregivers and development of psychological disorders are directly related with the duration of care-giving [4], severity of disease among the patients' and caregivers' coping strategies [5]. Severe and long term stress associated with care-giving potentially impose caregivers to subclinical or clinical anxiety and depression [6].

Spirituality-based modalities are within cognitive and behavioral interventions that may help caregivers to better cope with stress, and more effectively handle stress associated with their responsibilities. Spirituality-based modalities have a humanistic approach and help individuals to search and find a spiritual meaning of life, in order to adapt when facing difficulties. Although religion is one kind of spirituality, spirituality has a more extensive meaning and includes meditation, yoga, arts, etc. In recent decades, the concept of spirituality has illustrated this theme more precisely [7].

Intelligence can be defined as the learning, talent, the whole acquired knowledge and the capability to cope with the environment. Based on a novel theoretical model, the following four layers of intelligence can be defined: physical intelligence (body awareness and skillful use), intellectual intelligence (math and verbal skills), emotional intelligence (management of relationships), and spiritual intelligence (the most sophisticated one which is limited to human kind) [7]. It is an abstract concept implying the employment of spiritual resources in practical situations, as a problem solving behavior [7] and looks for meaning and ultimate goal of life [8]. It seems that the relationship between adjustability and spirituality is mediated by spiritual intelligence [7].

A good deal of research shows that spirituality is related to the individual's health, as well as the onset and progression of the mental distress and physical disorders [9-11]. Multiple studies have demonstrated a significant relationship between the spirituality and different domains of mental health $[12$, 
13]. It has been shown that spirituality predicts self-efficacy [14], happiness [15] and quality of life [16] in various populations. Personality characteristics [12] and childhood spiritual experiences [17] may shape the SI.

In this study, we hypothesized that spirituality may have a protective effect on mental health of caregivers of patients with Alzheimer's disease. It has been suggested that individuals at stress may benefit from spiritual behaviors, as a coping strategy, more than controls $[18,19]$. The amount of caregiver burden, on one hand is reversely related to spiritual well-being [18], and on the other hand it is related to the development of depression [20].

In addition, recent studies have mentioned spirituality as an important predictor of quality of nursing care and prevention of burnout in nurses. These studies have shown the impact of spirituality on emotional intelligence and both factors on the quality of nursing care $[21,22]$.

As there had been only few - if any - investigations assessing the spirituality among caregivers, this study was planned to assess the association between spirituality, depression and anxiety among caregivers of patients with the Alzheimer's disease. Given the fact that spirituality is a modifiable factor that can be improved by specific interventions, if spirituality is correlated with depression and anxiety, it can be targeted by programs supporting the caregivers, in order to promote mental health and familial burden of the illness to the society.

\section{Methods}

\subsection{Design and Setting}

In this correlational study, after the approval of the research planned by the research committee of Mashhad university of medical sciences, and then a pilot study of 30 individuals, 209 individuals from caregivers of patients with Alzheimer's disease referring to the outpatient Neuropsychiatry clinic of the Avicenna hospital of Mashhad, northeast of Iran, during 2011-2012, were selected using the purposive sampling method.

The inclusion criteria were caregiving of patients with moderate Alzheimer's disease at home. Primarily, patients with Alzheimer's disease were diagnosed by a psycho-geriatrist using a semi-structured interview based on DSM-IV criteria. Then, the MMSE test was used to indicate the patients with moderate Alzheimer's disease (MMSE=10-20). Exclusion criteria were history of any major physical or mental disorder in caregivers or their family. After explaining the plan and privacy of the questionnaires for candidates, they signed an informed consent and participated voluntarily. Afterwards, the demographic characteristics of patients and caregivers were recorded. Finally, Hospital Anxiety-Depression Scale (HADS) and Sohrabi's Spiritual Intelligence Questionnaire were fulfilled by caregivers, under the supervision of psychiatry residents.

\subsection{MMSE (Minimal Mental Status Examination)}

It is a therapist administrated test for screening and indicating the severity of dementia. It assesses various domains involved in dementia (11 items). The maximum score is 30 and the cut off score for dementia is 24 . The scores ranging from 20-24, 10-20 and less than 10 are indicated mild, moderate and severe dementia respectively. Cronbach's alpha for Iranian version has been 0.78 [23].

\subsection{Symptoms of Anxiety and Depression}

The Hospital Anxiety-Depression scale is extensively validated in the general population, was first introduced by Snaith and Zigmond in 1982 [24, 25]. It consists of 7 questions for assessing depression and 7 questions for assessing anxiety, so data gathering by HADs is fast. The maximum score in each subscale is 21 and the scores of 0-7, 8-10 and 11-21 indicate non-symptomatic situation, mild depression or anxiety and clinical depression or anxiety respectively. This test is capable to differentiate between physical and mental symptoms. The total score of the test (maximum=42) is a reflection of emotional status [25]. Cronbach's alpha of the Iranian version of depression and anxiety sub-scale have been 0.70 and 0.85 respectively [24].

\subsection{Spirituality}

As spirituality is quite affected by culture, an Iranian questionnaire made by Sohrabi was used to assess spiritual intelligence. It consists of 97 questions and evaluates 8 dimensions of spirituality (Diagram 1). The total score ranges from 97 to 388, without any certain cutoff. Higher scores indicate higher SI. Cronbach's alpha has been 0.98 [26], higher than other tests for spiritual intelligence [27].

\subsection{Data Analysis}

Data were analyzed by SPSS software version 13 using Spearman, Pearson, ANOVA, and Posthoc analysis (Tukey test). P less than 0.05 was considered statistically significant.

\section{Results}

Overall, 209 Alzheimer caregivers were included in this study, which composed of 135 women and 74 men, with a mean age of $43.7 \pm 12.0$ years. Most participants were married (93.3\%), had completed high school (55\%) and reported medium economic status (79.9\%), and based on self-assessments. Among the caregiver demographics, only economic status had relationship with spirituality $(\mathrm{F}=4.745, \mathrm{P}=0.010)$. Tukey's test showed that only the difference between poor and moderate economic statuses is significant $(\mathrm{P}=0.008)$; the poor group had more spirituality than the moderate group (table 1).

Mean scores of SI, depression, anxiety and total HADS score were $247.0 \pm 29.2,7.1 \pm 2.2,6.8 \pm 2.3$ and $13.9 \pm 3.2$ respectively. Mean scores of eight dimensions of spirituality are presented in table 2 . The prevalence of depression and anxiety was $45.4 \%$ (36.4\% mild and 9\% clinical depression) and $47.3 \%$ ( $45 \%$ mild and $2.3 \%$ clinical depression). The prevalence of coexisted depression and anxiety was $23 \%$.

There was not any significant association between gender and symptoms of depression, anxiety, total HADS score, and spirituality dimensions (table 2).

Spearman correlation test suggested that among caregivers, severity of depression symptoms was reversely 
correlated with spirituality $(\mathrm{r}=-0.436, \mathrm{P}<0.001)$, however, the correlation between anxiety symptoms and spirituality was not significant $(\mathrm{r}=0.061, \mathrm{P}=0.384)$.
Also, Pearson correlation indicated that spirituality reversely correlated with total HADS scores ( $r=-$ $0.262, \mathrm{P}<0.001$ ) (table 3).

Table 1. Demographic characteristics of Alzheimer patients and caregivers

\begin{tabular}{|c|c|c|c|c|c|c|}
\hline \multirow{2}{*}{ Variable } & & \multicolumn{2}{|c|}{ Patients } & \multicolumn{3}{|r|}{ Caregivers } \\
\hline & & Frequency & Percentage & Frequency & Percentage & Association with Spiritual Intelligence \\
\hline \multirow{7}{*}{ Age } & $20-29$ & 0 & 0 & 36 & 17.2 & \multirow{7}{*}{$\begin{array}{c}\mathrm{r}=0.115 \\
\mathrm{P}=0.099^{\mathrm{a}}\end{array}$} \\
\hline & $30-39$ & 0 & 0 & 49 & 23.4 & \\
\hline & $40-49$ & 0 & 0 & 40 & 19.1 & \\
\hline & $50-59$ & 0 & 0 & 70 & 33.5 & \\
\hline & $60-69$ & 58 & 27.8 & 14 & 6.7 & \\
\hline & $70-79$ & 135 & 64.6 & 36 & 0 & \\
\hline & $80-89$ & 16 & 7.7 & 49 & 0 & \\
\hline \multirow{2}{*}{ Gender } & Female & 131 & 62.7 & 135 & 64.6 & \multirow{2}{*}{$\begin{array}{c}\mathrm{t}=0.271 \\
\mathrm{P}=0.787^{\mathrm{b}}\end{array}$} \\
\hline & Male & 78 & 37.3 & 74 & 35.4 & \\
\hline \multirow{3}{*}{ Education } & Illiterate & 45 & 21.5 & 13 & 6.2 & \multirow{3}{*}{$\begin{array}{l}\mathrm{F}=0.735 \\
\mathrm{P}=0.532^{\mathrm{c}}\end{array}$} \\
\hline & Primary & 65 & 31.3 & 38 & 18.2 & \\
\hline & Tertiary & 20 & 9.6 & 43 & 20.6 & \\
\hline \multirow{3}{*}{ Economic status } & Poor & 27 & 12.9 & 27 & 12.9 & \multirow{3}{*}{$\begin{array}{l}\mathrm{F}=4.745 \\
\mathrm{P}=0.010^{\mathrm{c}}\end{array}$} \\
\hline & Moderate & 167 & 79.9 & 167 & 79.9 & \\
\hline & Rich & 15 & 7.2 & 15 & 7.2 & \\
\hline \multirow{3}{*}{ Marital status } & Single & 2 & 1.0 & 10 & 4.8 & \multirow{3}{*}{$\begin{array}{l}\mathrm{F}=0.931 \\
\mathrm{P}=0.396^{\mathrm{c}}\end{array}$} \\
\hline & Married & 176 & 84.2 & 195 & 93.3 & \\
\hline & Divorced /Widow & 31 & 14.8 & 4 & 1.9 & \\
\hline
\end{tabular}

a Spearman test

$\mathrm{b}$ Independent $\mathrm{t}$ test

${ }^{c}$ ANOVA test

$\mathrm{P}=\mathrm{P}$-value

Table 2. Mean scores of spirituality, anxiety, and depression in female and male caregivers of patients with Alzheimer's disease

\begin{tabular}{|c|c|c|c|c|}
\hline Item & Gender & Mean & SD & \\
\hline \multirow[t]{2}{*}{ Depression } & Female & 7.1 & 2.2 & $Z=-0.292$ \\
\hline & Male & 7.1 & 2.3 & $\mathrm{P}=0.770^{\mathrm{a}}$ \\
\hline Anxiety & Male & 7.0 & 2.2 & $\mathrm{P}=0.320^{\mathrm{a}}$ \\
\hline \multirow[t]{2}{*}{ Total HADS } & Female & 13.9 & 3.4 & $t=-0.509$ \\
\hline & Male & 14.1 & 2.8 & $\mathrm{P}=0.611^{\mathrm{b}}$ \\
\hline Total spirituality & Male & 246.3 & 28.2 & $\mathrm{P}=0.787^{\mathrm{b}}$ \\
\hline \multirow{2}{*}{ Patience } & Female & 25.6 & 5.4 & $\mathrm{t}=1.007$ \\
\hline & Male & 24.8 & 5.9 & $\mathrm{P}=0.315^{\mathrm{b}}$ \\
\hline \multirow[t]{2}{*}{ Spiritual believes and behaviors } & Female & 33.6 & 9.3 & $\mathrm{t}=1.933$ \\
\hline & Male & 31.1 & 8.7 & $\mathrm{P}=0.055^{\mathrm{b}}$ \\
\hline \multirow[t]{2}{*}{ Meaning and goal of life } & Female & 33.1 & 6.9 & $\mathrm{t}=0.139$ \\
\hline & Male & 32.9 & 7.1 & $\mathrm{P}=0.847^{\mathrm{b}}$ \\
\hline Thralldom & Male & 28.3 & 5.0 & $\mathrm{P}=0.192^{\mathrm{b}}$ \\
\hline \multirow[t]{2}{*}{ Internal calm } & Female & 26.9 & 5.6 & $\mathrm{t}=0.421$ \\
\hline & Male & 26.5 & 5.3 & $\mathrm{P}=0.647^{\mathrm{b}}$ \\
\hline \multirow[t]{2}{*}{ Spiritual experiences } & Female & 26.9 & 6.3 & $\mathrm{t}=0.036$ \\
\hline & Male & 26.8 & 6.7 & $\mathrm{P}=0.971^{\mathrm{b}}$ \\
\hline \multirow[t]{2}{*}{ Self-cognition } & Female & 42.2 & 15.2 & $t=-0.703$ \\
\hline & Male & 43.7 & 13.8 & $\mathrm{P}=0.483^{\mathrm{b}}$ \\
\hline \multirow[t]{2}{*}{ Forgiveness } & Female & 28.2 & 8.6 & $\mathrm{t}=-0.401$ \\
\hline & Male & 28.7 & 8.2 & $\mathrm{P}=0.689^{\mathrm{b}}$ \\
\hline
\end{tabular}

${ }^{\text {a }}$ Mann-Whitney test

${ }^{\mathrm{b}}$ Independent $\mathrm{t}$ test

$\mathrm{P}=\mathrm{P}$-value

$\mathrm{SD}=$ Standard Deviation

HADS=Hospital Anxiety-Depression Scale

$\mathrm{SI}=$ spiritual intelligence 
Table 3. Correlation between anxiety, depression, and spirituality dimensions among caregivers of Alzheimer patients

\begin{tabular}{|c|c|c|c|c|}
\hline & & Depression & Anxiety & Total HADS \\
\hline \multirow[t]{2}{*}{ Total SI } & $r$ & -0.436 & 0.061 & -0.262 \\
\hline & $\mathrm{P}$ & $<0.001^{\mathrm{a}}$ & $0.384^{\mathrm{a}}$ & $<0.001^{\mathrm{b}}$ \\
\hline \multirow[t]{2}{*}{ Patience } & $r$ & -0.073 & -0.073 & -0.104 \\
\hline & $\mathrm{P}$ & $0.295^{\mathrm{a}}$ & $0.295^{\mathrm{a}}$ & $0.132^{\mathrm{b}}$ \\
\hline \multirow[t]{2}{*}{ Spiritual believes and behaviors } & $\mathrm{r}$ & -0.056 & 0.216 & 0.119 \\
\hline & $\mathrm{P}$ & $<0.420^{\mathrm{a}}$ & $0.002^{\mathrm{a}}$ & $0.086^{\mathrm{b}}$ \\
\hline \multirow[t]{2}{*}{ Meaning and goal of life } & $\mathrm{r}$ & -0.071 & -0.003 & -0.052 \\
\hline & $\mathrm{P}$ & $0.307^{\mathrm{a}}$ & $0.961^{\mathrm{a}}$ & $0.451^{\mathrm{b}}$ \\
\hline \multirow[t]{2}{*}{ Thralldom } & $\mathrm{r}$ & -0.104 & 0.079 & -0.015 \\
\hline & $\mathrm{P}$ & $0.135^{\mathrm{a}}$ & $0.254^{\mathrm{a}}$ & $0.831^{\mathrm{b}}$ \\
\hline \multirow[t]{2}{*}{ Internal calm } & $\mathrm{r}$ & 0.124 & -0.724 & -0.443 \\
\hline & $\mathrm{P}$ & $<0.001^{\mathrm{a}}$ & $<0.001^{\mathrm{a}}$ & $<0.001^{\mathrm{b}}$ \\
\hline \multirow[t]{2}{*}{ Spiritual experiences } & $\mathrm{r}$ & -0.149 & 0.090 & -0.038 \\
\hline & $\mathrm{P}$ & $0.032^{\mathrm{a}}$ & $0.194^{\mathrm{a}}$ & $0.582^{\mathrm{b}}$ \\
\hline Self-cognition & $\mathrm{P}$ & $<0.001^{\mathrm{a}}$ & $0.076^{\mathrm{a}}$ & $0.138^{\mathrm{b}}$ \\
\hline \multirow[t]{2}{*}{ Forgiveness } & $\mathrm{r}$ & -0.789 & 0.169 & -0.431 \\
\hline & $\mathrm{P}$ & $0.001^{\mathrm{a}}$ & $0.014^{\mathrm{a}}$ & $<0.001^{\mathrm{b}}$ \\
\hline
\end{tabular}

${ }^{a}$ Spearman correlation test

${ }^{\mathrm{b}}$ Pearson correlation test

HADS=Hospital Anxiety-Depression Scale

$\mathrm{P}=\mathrm{P}$-value

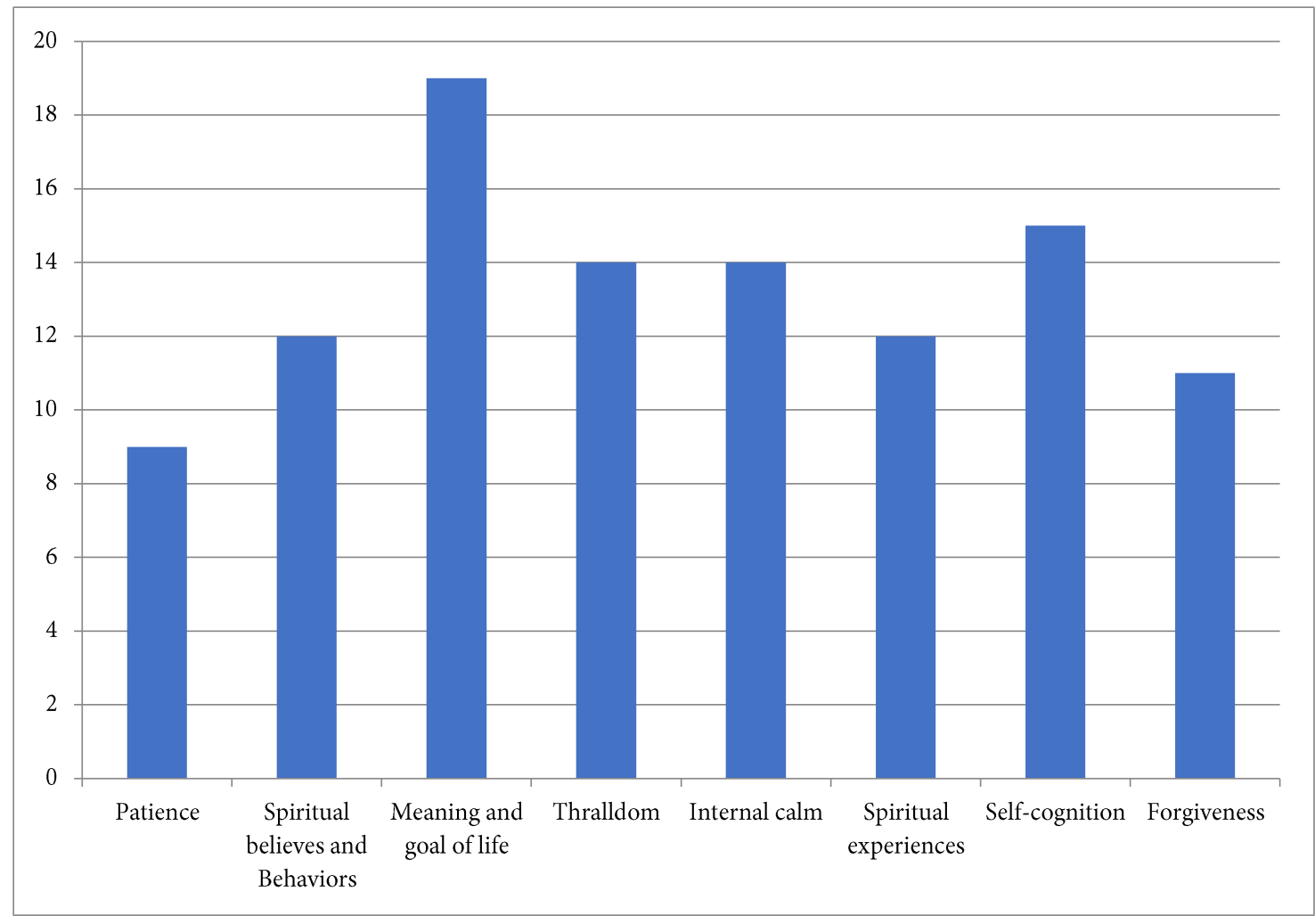

Diagram 1. Eight dimensions of spirituality in Alzheimer caregivers

\section{Discussion}

Unfortunately various treatment modalities for Alzheimer's disease do not control the patients' symptoms sufficiently, thus experts have shown an increasing interest in focusing on the caregivers burden. Present study showed high symptoms of depression and anxiety among caregivers (45\% and $47 \%$ respectively). Regarding depression, it was consistent with most of the prior research. Mausbach showed that $40 \%$ of caregivers of patients with Alzheimer's disease (compared with only $5 \%$ of non-caregivers) had depression [6]. Also, Gallagher stated that $46 \%$ of caregivers who were seeking help have depression, whereas it was only $18 \%$ in non-helpseekers [28]. However, Mahoney showed that only $10.1 \%$ of caregivers are suffering from depression and anxiety (24\%) is more common [29].

Prior research introduces caregiver's age, gender, physical abilities, personality characteristics, health status, employment status, available supporting services and severity of symptoms in patients, as predisposing or protecting factors against depression. Gender, health, living with patient, and relationship with patient predisposed caregivers toward anxiety [29]. In the present study, gender was not associated with 
caregivers' high depressive or anxiety symptoms.

Based on our findings, spirituality was linked to mental health. Spurlock showed that the amount of stress that is experienced by caregivers is reversely related to their spiritual well-being [18]. Other studies have also emphasized the role of the spirituality in predicting nurses caring behaviors and preventing their burnout $[21,22]$.

In the present study, 23\% had coexisting high levels of depression and anxiety. Therefore, if a caregiver has one of these high symptoms, with almost $50 \%$ probability, it can be predicted that she/he has the other symptoms too. The rate of coexistence of anxiety and depressive disorders has been reported between $30-65 \%$ in various populations [30] and approximately $60 \%$ in Iran [31].

In the present study, spiritual intelligence reversely correlated with total the HADS score and depression subscale. Consistent with our results, prior studies have shown that spirituality has a significant direct relationship with mental health $[13,15,17]$, self-efficacy [14] and quality of life [16]. Also, spirituality and spiritual well-being have been reversely related with depression in the general population [32], elderly [33] and heart failure [34] and with anxiety and depression in patients with cancer [35]. However, anxiety in the present study did not have a significant correlation with spirituality. It is probable that spirituality acts as a coping instrument in chronic unfavorable situations (causing depression) $[36,37]$. However, for declaring the definite comment more investigations are required.

Dysfunctional coping strategies and coexisting depression are among factors predicting the anxiety in caregivers [38] and they may have affected the relationship between spirituality and anxiety in the present study too. Patient's irritability and impaired relationship between patient and caregiver affect each other. It has been said that patient- caregiver relationship can predict, the higher rate of anxiety and depression in caregiver [29] and this may affect the relationship between anxiety and spiritual intelligence in our study too. On the other hand, personal characteristics, such as anxious trait, play a role in the development of anxiety and depression [39]. Utilizing high spirituality, a person may compensate these traits to some extent, but he/she is not often able to eliminate their outcomes completely, to reduce the risk of depressive and anxiety disorders [40]. However, a good deal of research is required to illustrate this theme thoroughly.

Regarding the factors affecting spirituality, consistent with prior results in students, this study showed that gender [15] and age [13] do not affect SI. Nevertheless, an investigation in nurses has shown that spirituality is affected by age and related childhood experiences [17]. This is more expected, because aging often accompanies with gaining more experiences, for instance spiritual experiences. Therefore, it seems that this theme requires more investigations. Generally, it seems that personality characteristics [12] have a more critical role to determine SI, than age.
In the present study, among the demographic characteristics, only economic status had a significant relationship with SI. Caregivers with poor and moderate economic statuses had the highest and lowest spirituality respectively, and only the difference between this pair was significant. Consistent with our results, Yiengprugsawan [41] showed that individuals with poor socioeconomic status, who pay more attention to religious and spiritual beliefs, have more social interactions and are more supported by family members. On the other hand, caregiving of patients with Alzheimer's disease, wastes a lot of cost, time, and job opportunities and perhaps expose the caregivers towards poverty. So, poverty may be an effect, not a cause. Also, the self-report of economic status may be affected by an individual's mental distress and spiritual status [42] and is not the absolute fact.

Spirituality has been suggested as an additive remedy for depression and anxiety [43]. So, spiritual exercises, such as yoga [44], prayer [43], and cognitive-behavioral plus spiritual counseling (CBSC) [45], have been able to increase mood and mindfulness and are suggested for prevention and treatment of depression and anxiety in caregivers of patients with Alzheimer's disease, as well. They make a lot of family members to take care of patients at home, instead of hospice.

\section{Conclusion}

Psychological distress - such as depression and anxiety symptoms- are prevalent in Alzheimer caregivers. It is not known how country level welfare-support systems contribute to this problem. Since spirituality may be associated with symptoms of depression in caregivers, interventions based on spirituality may be effective to promote mental health and quality of life of caregivers [46, 47].

Nevertheless, more extensive descriptive and intervention studies are required, before adding the spiritual counseling to routine helping programs for caregivers.

\section{Limitations and Suggestions}

Lack of studies focused on the theme of spirituality in caregivers of patients with Alzheimer's disease, shortage of studies about spirituality in caregivers, inconsistent results of these few investigations, made comparisons difficult. Therefore, more extended studies, including control group are recommended to be followed by this study. As the present study was cross-sectional, it was not possible to detect cause and effect relationships. Thus, longitudinal studies are suggested. This was one of the first times that the relationship between spirituality with symptoms of depression and anxiety was evaluated among Alzheimer caregivers, and to some extent highlights the need for subsequent research.

\section{Acknowledgements}

We thank the Vice Chancellor of Mashhad University of Medical Sciences and staff of outpatient clinic of the Avicenna Hospital. 


\section{Authors' Contribution}

Roya Samadi: design - drafting and revising the manuscript. ${ }^{*}$ Naghmeh Mokhber: data acqusion - study design, contribution to the manuscript Farhad Faridhosseini: contribution to the manuscript draft and revision. Mehri Baghban Haghighi: data analysis, manuscript draft. Shervin Assari: contribution to the manuscript draft and revision

\section{Funding/Support}

This research was performed as e residency thesis after the approval by the research committee of the university. This research received a grant from the Vice Chancellor of Research of the Mashhad University of Medical Sciences.

\section{Financial Discloser}

The authors have no conflict of interests to disclose.

\section{References}

1. Lopes MA, Hototian SR, Bustamante SE, Azevedo D, Tatsch M, Bazzarella MC, et al. Prevalence of cognitive and functional impairment in a community sample in Ribeirao Preto, Brazil. Int $\mathrm{J}$ Geriatr Psychiatry. 2007;22(8):770-6.

2. Zuidema SU, de Jonghe JF, Verhey FR, Koopmans RT. Neuropsychiatric symptoms in nursing home patients: factor structure invariance of the Dutch nursing home version of the neuropsychiatric inventory in different stages of dementia. Dement Geriatr Cognit Disord. 2007;24(3):169-76.

3. Amieva H, Rullier L, Bouisson J, Dartigues JF, Dubois O, Salamon R. [Needs and expectations of Alzheimer's disease family caregivers]. Rev Epidemiol Sante Publique.. 2012;60(3):231-8.

4. Gonzalez-Salvador MT, Arango C, Lyketsos CG, Barba AC. The stress and psychological morbidity of the Alzheimer patient caregiver. Int J Geriatr Psychiatry. 1999;14(9):701-10.

5. Zucchella C, Bartolo M, Pasotti C, Chiapella L, Sinforiani E. Caregiver burden and coping in early-stage Alzheimer disease. Alzheimer Dis Assoc Disord. 2012;26(1):55-60.

6. Mausbach BT, Chattillion EA, Roepke SK, Patterson TL, Grant I. A comparison of psychosocial outcomes in elderly Alzheimer caregivers and noncaregivers. Am J Geriatr Psychiatry. 2013;21(1):5-13.

7. Abdollahzadeh H BpM, Bouj Mehrani S, Lotfi M. Spritual intelligence: Concepts, Assessment and Applications. Tehran: Psychometric Publications; 2009. Persian

8. Zohar D MI. Spiritual Intelligence: The Ultimate Intelligence. New York: Bloomsbury Publishing PLC; 2001.

9. George LK LD, Koeing, Mccullough ME Spirituality and health: What we know, what we need to know. J Soc Clin Psychol. 2000;19(1):102-16

10. Allen RS, Harris GM, Crowther MR, Oliver JS, Cavanaugh R, Phillips LL. Does religiousness and spirituality moderate the relations between physical and mental health among aging prisoners? Int J Geriatr Psychiatry. 2013;28(7):710-7.

11. Krumrei EJ, Pirutinsky S, Rosmarin DH. Jewish spirituality, depression, and health: an empirical test of a conceptual framework. Int J Behav Med. 2013;20(3):327-36.

12. Abedei $F$. The relation between spiritual intelligence and personality characteristics in individual between 19-50 years old in Sari. Behshahr: Payam Noor University; 2009. Persian

13. Shabani J, Hassan SA, Ahmad A, Baba M. Moderating influence of gender on the link of spiritual and emotional intelligences with mental health among adolescents. Life Sci J. 2011;8(1):106-12.

14. Gupta, G. Spiritual intelligence and emotional intelligence in relation to self-efficacy and self-regulation among college students. Int J Social Sci Interdisciplinary Res. 2012;1(2):60-9.

15. Yaghoobi A. The study of relation between spiritual intelligence and rate of happiness in booali university students. J Res Edu System. 2010;4(9):85-95.

16. Bolghan-Abadi M, Ghofrani F, Abde-Khodaei MS. Study of the Spiritual Intelligence Role in Predicting University Students' Quality of Life. J Relig Health. 2014;53(1):79-85.

17. Yang KP. The spiritual intelligence of nurses in Taiwan. J Nurs Res. 2006;14(1):24-35.
18. Spurlock WR. Spiritual well-being and caregiver burden in Alzheimer's caregivers. Geriatr Nurs. 2005;26(3):154-61.

19. Kaye J, Robinson KM. Spirituality among caregivers. Image J Nurs Sch. 1994;26(3):218-21.

20. Wanchae P. Spirituality, depression and caregiver burden among family caregivers of Alzheimer's disease patients. California: California State University 2006.

21. Adamson E. Caring behaviour of nurses in Malaysia is influenced by spiritual and emotional intelligence, psychological ownership and burnout. Evid Based Nurs. 2014;17(4):121.

22. Kaur D, Sambasivan M, Kumar N. Effect of spiritual intelligence, emotional intelligence, psychological ownership and burnout on caring behaviour of nurses: a cross-sectional study. J Clin Nurs. 2013;22(21-22):3192-202.

23. Foroughan m, Jafari Z, Shiri BP, Ghaem Magham Faraahani Z, Rahgozar M. Validation of mini-mental state examination (MMSE) in the elderly population of Tehran. Adv Cogn Sci. 2008; 38, 29-37

24. Kaviani H, Seyfourian H, Sharifi V, Ebrahimkhani N. Reliability and validity of Anxiety and Depression Hospital Scales (HADS): Iranian patients with anxiety and depression disorders. TUMJ. 2009;67(5):379-85.Persian

25. Zigmond AS, Snaith RP. The hospital anxiety and depression scale. Acta Psychiatr Scand. 1983;67(6):361-70.

26. Sohrabi F, Naseri E. A study of the conception and components of spiritual of intelligence and developing and instrument to assess it. Res Psychological Health. 2009;2(4):69-77.Persian

27. King DB, DeCicco TL. A viable model and self-report measure of spiritual intelligence. International Journal of Transpersonal Studies. 2009; 28(1):68-85.

28. Gallagher D, Rose J, Rivera P, Lovett S, Thompson LW. Prevalence of depression in family caregivers. The Gerontologist. 1989;29(4):449-56.

29. Mahoney R, Regan C, Katona C, Livingston G. Anxiety and depression in family caregivers of people with Alzheimer disease: the LASER-AD study. Am J Geriatr Psychiatry. 2005;13(9):795-801.

30. Nutt DJ. Depression, anxiety and the mixed conditions. New York: Wiley; 1997.

31. Kaviani H, Ghasemzadeh H. The Comorbidity Of Depression And Anxiety In A Sample of Iranian Patients. TUMJ. 2003;61(3):1717.Persian

32. Maselko J, Gilman SE, Buka S. Religious service attendance and spiritual well-being are differentially associated with risk of major depression. Psychol Med. . 2009;39(6):1009-17

33. Park J, Roh S. Daily spiritual experiences, social support, and depression among elderly Korean immigrants. Aging Ment Health. 2013;17(1):102-8.

34. Bekelman DB, Dy SM, Becker DM, Wittstein IS, Hendricks DE, Yamashita TE, et al. Spiritual well-being and depression in patients with heart failure. J General Internal Med. 2007;22(4):470-7.

35. Boscaglia N, Clarke DM, Jobling TW, Quinn MA. The contribution of spirituality and spiritual coping to anxiety and depression in women with a recent diagnosis of gynecological cancer. Int J Gynecol Cancer. 2005;15(5):755-61.

36. Greenstreet W. From spirituality to coping strategy: making sense of chronic illness. Br J Nurs. 2006;15(17):938-42.

37. Post SG, Puchalski CM, Larson DB. Physicians and patient spirituality: professional boundaries, competency, and ethics. Ann Intern Med. 2000;132(7):578-83

38. Cooper C, Katona C, Orrell M, Livingston G. Coping strategies and anxiety in caregivers of people with Alzheimer's disease: the LASER-AD study. J Affect Disord. 2006;90(1):15-20.

39. Min J-A, Jung Y-E, Kim D-J, Yim H-W, Kim J-J, Kim T-S, et al. Characteristics associated with low resilience in patients with depression and/or anxiety disorders. Qual Life Res.2013;22(2):23141.

40. Koenig HG. Research on religion, spirituality, and mental health: a review. Can J Psychiatry. 2009;54(5):283-91.

41. Yiengprugsawan V, Seubsman SA, Lim L, Sleigh A, the Thai Cohort Study T. Social Capital, Trust, Economic Stress and Religion in a Cohort of 87,134 Thai Adults. Warasan Prachakon Lae Sangkhom. 2011;19(2):183-96.

42. Park NS, Lee BS, Sun F, Klemmack DL, Roff LL, Koenig HG. Typologies of religiousness/spirituality: implications for health and well-being. J Relig Health. 2013;52(3):828-39.

43. Boelens PA, Reeves RR, Replogle WH, Koenig HG. The effect of prayer on depression and anxiety: maintenance of positive influence one year after prayer intervention. Int $\mathrm{J}$ Psychiatry Med. 2012;43(1):85-98.

44. Bussing A, Hedtstuck A, Khalsa SB, Ostermann T, Heusser P. Development of Specific Aspects of Spirituality during a 6-Month 
Intensive Yoga Practice. Evid Based Complement Alternat Med. 2012;2012:981523.

45. Glueckauf RL, Davis WS, Allen K, Chipi P, Schettini G, Tegen L, et al. Integrative cognitive-behavioral and spiritual counseling for rura dementia caregivers with depression. Rehabil Psychol. 2009;54(4):449-61.
46. Cotton S, Zebracki K, Rosenthal SL, Tsevat J, Drotar D. Religion/spirituality and adolescent health outcomes: a review. The J Adolesc Health. 2006;38(4):472-80.

47. D'Souza R. The importance of spirituality in medicine and its application to clinical practice. Med J Aust. 2007;186(10 Suppl):S579. 